\title{
Programa de hemodiálisis diaria domiciliaria. Alternativa con futuro
}

\author{
Encarnación Fernández Prado \\ Enfermera del servicio de nefrología. Hospital de Galdakao. Vizcaya
}

\section{Sr. Director:}

Los beneficios de la HD diaria y la participación del paciente crónico en su propio tratamiento son bien conocidos.

Gracias a la seguridad y eficacia que hoy en día nos ofrecen los monitores de diálisis y los equipos de tratamiento de agua, se vuelve a contemplar la HD domiciliaría como una alternativa más al tratamiento renal sustitutivo.

Presentamos la experiencia de 8 años, de una modalidad de diálisis poco frecuente en nuestro entorno: Hemodiálisis Diaria Domiciliaria (HD-DD).

Describimos:

- La organización para su puesta en marcha.

- Planificación del entrenamiento.

- Pauta de hemodiálisis.

- Seguimiento e incidencias.

- Analizamos resultados clínicos y analíticos antes de iniciar con HD-DD y al año.

\section{Material y método}

Para su puesta en marcha a parte de los permisos oficiales para realizar la nueva técnica se requirió la incorporación de una enfermera con experiencia en HD y la utilización de un BOX del área de DP para el entrenamiento.

Se establecieron unos requisitos de inclusión para el paciente y ayudante y con la empresa de diálisis contratada se fijaron las necesidades de acondicionamiento en el domicilio.Siempre se requirió una pequeña obra.

Se elaboró un programa de entrenamiento y un manual didáctico para el paciente y ayudante, que lo fuimos mejorando añadiendo material fotográfico.

5 pacientes han estado en nuestro programa , 4 hombres y 1 mujer, en un periodo de 6 meses el que menos y 6 años el que más. 2 pacientes han dejado el programa uno por trasplante y otro por fallecimiento en la actualidad continúan 3.

Iniciaron con una edad media de 49.2 años, un rango de 34-56.

La procedencia fue variada: 1 de diálisis peritoneal por fallo de membrana, 2 de HD hospitalaria, 1 de TX y 1 de la consulta de prediálisis.

Todos son portadores de FAVI y en todos los casos el cónyuge es el que participa en el tratamiento.

\section{Entrenamiento}

Excepto un paciente, todos incluido sus ayudantes tienen una vida laboral activa, lo cual se tiene en cuenta para la planificación del entrenamiento.

El entrenamiento ha durado una media de 4 meses.

Comienzan haciendo 3 HD a la semana, acuden los dos y se les va instruyendo en la técnica, realizándose una evaluación continúa de los conocimientos. Además de la técnica en sí también se les adiestra en el cuidado de la dieta, en el cuidado y control del material y cuidados en la recogida de los residuos.

A partir de la $8^{\mathrm{a}}-10^{\mathrm{a}}$ semana, cuando dominan la conexión y la desconexión y son capaces de resolver problemas con cierta seguridad, inician una 4 a sesión, ellos solos en el Box, en turno de tarde y generalmente Sábados (tienen la sala de crónicos cerca a la que acuden si necesitan). 
2 semanas antes de iniciar en domicilio realizan todas las HD solos.

Antes de iniciar en domicilio se realiza una revisión técnica de la instalación y se toman muestras de agua para analizar.

A la $1^{\mathrm{a}} \mathrm{HD}$ en domicilio acude la enfermera entrenadora y el técnico de la empresa de diálisis concertada.

\section{Pauta de hemodiálisis}

La pauta es de 5 días a la semana $2.5 \mathrm{~h}$, con los descansos siempre alternos, 1 de los pacientes presentados realiza 3 días $2.5 \mathrm{~h}$ y 2 días $3 \mathrm{~h}$

La pauta siempre es personalizada.

Monitor 4008 S FRESENIUS unido al equipo de osmosis inversa AQUA UNO.

Qb $350 \mathrm{ml} / \mathrm{m}$.

Dializador Helixona de alta permeabilidad FX 60.

Aguja de Fístula de $16 \mathrm{G}$.

Heparina de bajo peso molecular.

\section{Seguimiento e incidencias}

El contacto telefónico es continuo sobre todo al principio. Si es preciso se acude al domicilio.

Al mes de iniciar se hace control analítico con KT/v. Los siguientes controles están protocolizados cada 2 meses, siempre acude la enfermera entrenadora al domicilio a realizar la extracción Pre y Post HD .Y se comprueba el cumplimiento del tratamiento.

Cada 3 meses se toma muestra del agua para control Bioquímico y bacteriológico.

El paciente acude al Hospital a revisión médica y a recoger medicación a Farmacia ambulatoria cada 3 meses.

INCIDENCIAS en estos 8 años:

- Del acceso: 1 paciente con problemas de flujo por una estenosis, precisó un injerto de vena crioconservada

- Hematomas: 2 ocasiones

- Nueva punción: 2 (por sangrado) 6 (por falta de flujo)
- Infusión de suero intradiálisis: 25 veces (encontrarse flojo o con T/A baja)

- Ninguna hipotensión brusca

- Ninguna coagulación de circuito

- Desconexiones anticipadas: 7 (Fallo técnico del 0smotizador)

- Fallos del monitor: 10 y del 0smotizador 15 La reparación suele ser en el día o en 24 horas

\section{Resultados}

La situación clínica de los pacientes es buena .Todos refieren encontrarse mucho mejor y contentos por la elección de la técnica .Buena adherencia al tratamiento y todos han adaptado la diálisis a su actividad diaria. No han precisado ingresos, la HTA se ha corregido, reduciendo o suspendiendo los hipotensores en todos los casos. Todos han aumentado de peso, mejora del apetito esto hace que no podamos prescindir de los quelantes del fósforo, todos los toman.

En cuanto a la anemia 3 pacientes no requieren EPO y a 2 se les reduce la dosis. Las necesidades de Hierro IV también se reducen.

TABLA 1. Resultados clínicos de anemia, necesidad de EPO y HTA (tratamiento), fósforo preinicio de HD-DD y al año, en 1 paciente a los 6 meses por fallecimiento.

\begin{tabular}{|c|c|c|c|c|c|}
\hline & & $\mathrm{Hb} 7 \mathrm{~g}$ & $\begin{array}{l}\text { Dosis } \\
\text { EPO }\end{array}$ & $\begin{array}{l}N^{0} \text { Anti } \\
\text { HTA/día }\end{array}$ & Fósforo \\
\hline \multirow[b]{2}{*}{$\begin{array}{c}\text { Paciente } \\
1\end{array}$} & DPA & 10.6 & 8000 & 2 & 5.76 \\
\hline & $\begin{array}{l}1 \text { AÑO } \\
\text { HDDD }\end{array}$ & 14 & 0 & 0 & 6.2 \\
\hline \multirow{2}{*}{$\begin{array}{c}\text { Paciente } \\
2\end{array}$} & $\mathrm{HDH}$ & 11.7 & 9000 & 0 & 4.53 \\
\hline & $\begin{array}{l}6 \text { meses } \\
\text { HDDD }\end{array}$ & 11.8 & 9000 & 0 & 4.08 \\
\hline \multirow{2}{*}{$\begin{array}{c}\text { Paciente } \\
3\end{array}$} & $\mathrm{HDH}$ & 12.1 & 4000 & 1 & 2.68 \\
\hline & $\begin{array}{l}1 \text { AÑO } \\
\text { HDDD }\end{array}$ & 14.5 & 0 & 0 & 4.37 \\
\hline \multirow{2}{*}{$\begin{array}{c}\text { Paciente } \\
4\end{array}$} & TXY HD & 11.4 & 10000 & 3 & 4.43 \\
\hline & $\begin{array}{l}1 \text { AÑO } \\
\text { HDDD }\end{array}$ & 12.7 & 6000 & 1 & 4.87 \\
\hline \multirow{2}{*}{$\begin{array}{c}\text { Paciente } \\
5\end{array}$} & $\begin{array}{c}\text { CTAY } \\
\text { HD }\end{array}$ & 12.5 & 6000 & 5 & 4.65 \\
\hline & $\begin{array}{l}1 \text { AÑO } \\
\text { HDDD }\end{array}$ & 13.2 & 0 & 0 & 6.2 \\
\hline
\end{tabular}

\section{Conclusiones}

Podemos decir que la HD-DD es una excelente opción, aunque sea para un número reducido de pacientes.

Viable para poder ser implantada por su seguridad y eficacia.

Porque les permite tener un buen estado clínico, mejor 
calidad de vida sin tener que trasladarse al Hospital en un horario establecido, mejor autocuidado y en esta época de crisis un ahorro.

El coste de la HD hospitalaria ( 3 sesiones semanales) en nuestro centro es de $36.291 €$ paciente/año a lo que se suma el transporte y la medicación. El coste de la HD domiciliaria (5 sesiones) es de $35.524 €$ no hay que sumarle el transporte y la medicaron se reduce considerablemente.

\section{Bibliografía}

1. Finkelstein F., Schiller B., et al. AT- Home short daily hemodialysis improves the long-term health- related quality of life. Kidney Int. 2012; 82: 561-569.

2. Abdel-Kader K, Unruh M. Benefits of short daily home hemodialysis in the FREEDOM. Study: is itabaut person, place, time, or treatment?. Kidney Int. $2012 ; 82$ : 511-513.

3. Suzuki H., Hoshi H., et al. New Modality of Dialysis Therapy: Peritoneal Dialysis first and Transition to Home Hemodialysis. Adv Perit Dial, 2012, 28: 106-111. 